SOI: $\underline{1.1 / \text { TAS }}$ DOI: $\underline{10.15863 / \text { TAS }}$ International Scientific Journal Theoretical \& Applied Science

p-ISSN: 2308-4944 (print) e-ISSN: 2409-0085 (online)

Year: $2018 \quad$ Issue: 12 Volume: 68

Published: $13.12 .2018 \quad$ http://T-Science.org

UDC 665.753.4
QR - Issue

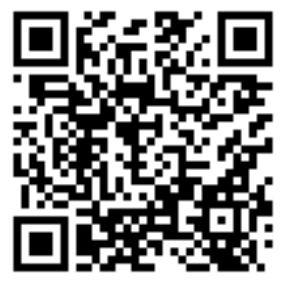

QR - Article

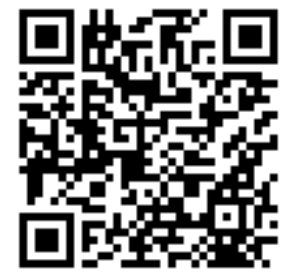

A.A. Yusif-Zadeh

Associate Professor of the Department "Petrochemical Technology and Industrial Ecology" Azerbaijan State University of Oil and Industry

A.Sh. Gurbanov Associate Professor of the Department" Petrochemical Technology and Industrial Ecology", Dean of the Magistracy Department Azerbaijan State University of Oil and Industry kerem_shixaliyev@mail.ru

\title{
MULTISTAGE EXTRACTION OF COKING GAS OIL TO PRODUCE A COMPONENT OF DIESEL FUEL
}

Abstract: The research devote to product oil of the diesel fuel component by multistage extraction of the coxing light gas oil (195-3500C) by double solvent, consisting from acetonitryl and pentane, taken in ratio 1:0,8. The optimum conditions purification were investigating by the three-and four stage extraction. The influence of the solvent amount by relation to raw material, number of stages purification have been researched by us. The base indices of purification degree of the coxing light gas oil are the cetane number, acid number, content of sulphuring elements. In result of purification the cetane number increased from 41 up to 49,5 units, the acid number decreased from 3,9 mg KOH up to 0,1 $\mathrm{mg} \mathrm{KOH,} \mathrm{an} \mathrm{amount} \mathrm{of} \mathrm{sulphuring} \mathrm{components} \mathrm{decreased} \mathrm{from} \mathrm{25,5} \mathrm{up} \mathrm{to} \mathrm{10,2} \mathrm{\%}$

Key words: coxing gas oil of extraction, acetonitryl, pentane, cetane number, iodine number, acid number, sulphuring components, refined oil, extract.

Language: Russian

Citation: Yusif-Zadeh, A. A., \& Gurbanov, A. S. (2018). Multistage extraction of coking gas oil to produce a component of diesel fuel. ISJ Theoretical \& Applied Science, 12 (68), 49-52.

Soi: http://s-o-i.org/1.1/TAS-12-68-9 Doi: crossef https://dx.doi.org/10.15863/TAS.2018.12.68.9

\section{МНОГОСТУПЕНЧАТАЯ ЭКСТРАКЦИЯ ГАЗОЙЛЯ КОКСОВАНИЯ ДЛЯ ПОЛУЧЕНИЯ КОМПОНЕНТА ДИЗЕЛЬНОГО ТОПЛИВА}

Аннотация: Исследования посвящены получению компонента дизельного топлива путём многоступенчатой экстракции лёгкого газойля коксования (195-3500С) двойным растворителем ацетонитрил с пентаном, взятым в соотношении 1:0,8. Изучались оптимальные условия очистки при трёхступенчатой и черытёхступенчатой экстракции. Нами изучалось влияние количества растворителя к сырью, число ступеней очистки. Основными показателями степени очистки лёгкого газойля коксования являются ацетановый индекс, кислотное число, содержание сульфирующихся элементов. В результате очистки иетановый индекс увеличился с 41 до 49,5 единиц, кислотное число упало с 3,9 мг КОН до 0,1 мг КОН, количество сульфирующихся компонентов с 25,5 до 10,2\%

Ключевые слова: газойль коксования, экстракция, ацетонитрил, пентан, цетановый индекс, йодное число, кислотное число, сульфирующиеся компоненты, рафинат, экстракт

\section{Introduction}

В последнее время наблюдается ужесточение требований к качеству дизельных топлив. Швеция уже в 1991 году предусматривала содержание серы от 10 до 50 ррм [1, 2]. США в октябре 1993 года ввела стандарт CARB, в котором содержание серы должно было быть не более 50 ррм [1]. В процессе замедленного коксования получается газойлевая фракция, выкипающая в пределах 195$350{ }^{\circ} \mathrm{C}$, которая в настоящее время на Бакинском нефтеперерабатывающем заводе им. Г.Алиева 


\begin{tabular}{|c|c|c|c|c|c|c|}
\hline \multirow{4}{*}{ Impact Factor: } & ISRA (India) & $=3.117$ & SIS (USA) & $=0.912$ & ICV (Poland) & $=6.630$ \\
\hline & ISI (Dubai, UAE & $=0.829$ & РИНЦ (Russia) & $=0.156$ & PIF (India) & $=1.940$ \\
\hline & GIF (Australia) & $=0.564$ & ESJI (KZ) & $=\mathbf{5 . 0 1 5}$ & IBI (India) & $=4.260$ \\
\hline & JIF & $=1.500$ & SJIF (Morocco) & $=5.667$ & & \\
\hline
\end{tabular}

частично возвращается в процесс как сырьё, либо сжигается в печах.

\section{Materials and Methods}

В дизельных топливах, содержащих вторичные дистилляты, при эксплуатации накапливаются продукты окисления, которые вступая в реакции конденсации и уплотнения образуют высокомолекулярные соединения, смолы и осадки. Смолы отлагаются на клапанах, форсунках, что повышает расход топлива и токсичность отработанных газов [3]. Кроме того, вторичные дистилляты содержат значительное количество ароматических и непредельных углеводородов. Как известно, многие ароматические углеводороды, сернистые и азотистые соединения хорошо экстрагируются полярными растворителями $[4,5,6]$.

Данные исследования посвящены получению компонента дизельного топлива путём многоступенчатой экстракции газойля коксования двойным растворителем ацетонитрил: пентан, взятого в соотношении 1:0,8 [3]. Характеристика используемого сырья приведены в таблице 1 .

Для определения минимального отношения растворителя к сырью, которое обеспечило бы получение стабильного компонента, нами проводились опыты с изменением числа ступеней экстракции и с изменением соотношения растворителя к сырью. Температуру экстракции всё время поддерживали $25^{\circ} \mathrm{C}$, хотя старались поддерживать температурный градиент разность температур сырья и растворителя 10$15^{\circ} \mathrm{C}$, что способствует чёткости разделения компонентов. Основное количество растворителя отгонялось простой перегонкой, так как температура кипения пентана $36^{\circ} \mathrm{C}$, а температура кипения ацетонитрила $78^{\circ} \mathrm{C}$.

\section{Таблица 1. Физико-химические характеристики сырья}

\begin{tabular}{|c|c|c|c|}
\hline № & Показатели & $\begin{array}{c}\text { Газойль замедленного коксования } \\
\left(195-350^{\circ} \mathrm{C}\right)\end{array}$ & Нормы по ТУ \\
\hline $\begin{array}{l}5 \\
6 \\
7 \\
8\end{array}$ & 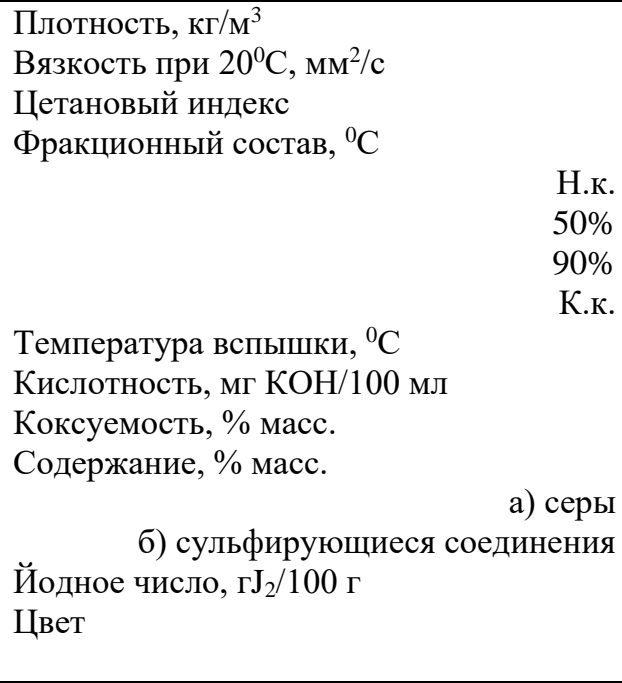 & $\begin{array}{c}196 \\
270 \\
335 \\
348 \\
64 \\
3,9 \\
0,21 \\
0,23 \\
25,5 \\
18,9 \\
\text { Тёмно-коричневый }\end{array}$ & $\begin{array}{c}\text { Не нормир. } \\
\text { 3,5-6,0 } \\
- \\
\text { - } \\
\text { Не более } 280 \\
\text { Не выше } 360 \\
\text { - } \\
\text { Не ниже } 45 \\
\text { - } \\
\text { - }\end{array}$ \\
\hline
\end{tabular}

Как видно из данных таблицы 1 газойль коксования характеризуется значительным содержанием серы, сульфирующихся соединений, не высоким цетановым индексом. Цетановый индекс рассчитывали по формуле (7):

$$
\text { Ц.И. }=454,74-1641,416 \rho_{4}^{15}+
$$

$774,74\left(\rho_{4}^{15}\right)^{2}+0,55 \tau_{50}+97,803\left(\log \tau_{50}\right)^{2}$ где $\rho_{4}^{15}$ - плотность при $15^{0} \mathrm{C}, \tau_{50}$-температура выкипания $50 \%$ объёмной фракции при атмосферном давлении, ${ }^{0} \mathrm{C}$.

В таблице 2 представлены качества рафината в зависимости от ступеней очистки.

Таблица 2. Результаты четырёхступенчатой экстракции газойля коксования

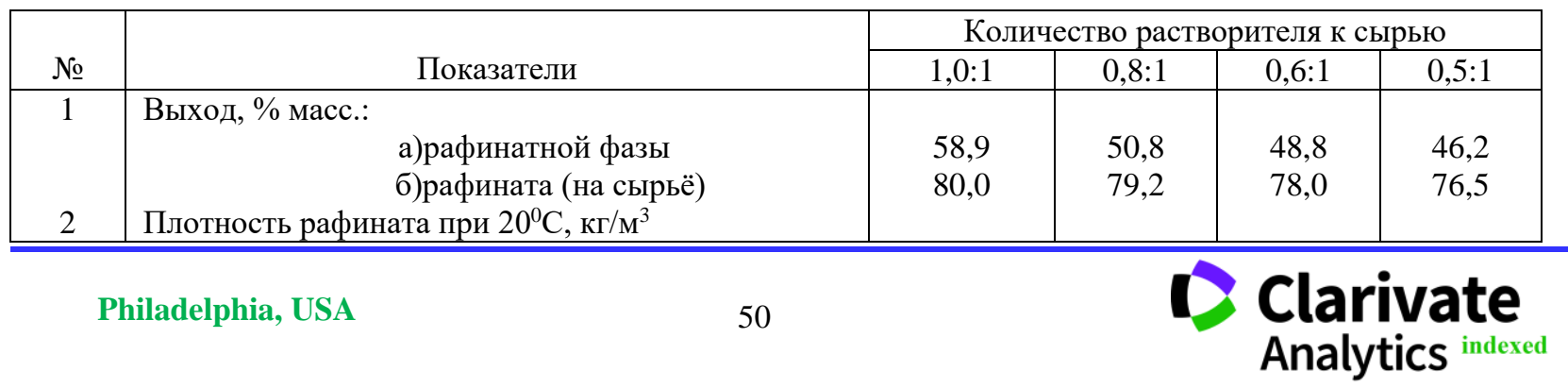




\begin{tabular}{|c|c|c|c|c|c|c|}
\hline \multirow{4}{*}{ Impact Factor: } & ISRA (India) & $=3.117$ & SIS (USA) & $=0.912$ & ICV (Poland) & $=6.630$ \\
\hline & ISI (Dubai, UAE & $=0.829$ & РИНЦ (Russia) & $=0.156$ & PIF (India) & $=1.940$ \\
\hline & GIF (Australia) & $=0.564$ & ESJI (KZ) & $=\mathbf{5 . 0 1 5}$ & IBI (India) & $=4.260$ \\
\hline & JIF & $=1.500$ & SJIF (Morocco) & $=5.667$ & & \\
\hline
\end{tabular}

\begin{tabular}{|c|l|c|c|c|c|}
\hline & Вязкость при 20ㅇ, мм²/c & 824 & 823 & 822 & 820 \\
3 & Содержание, \% масс.: & 3,25 & 3,18 & 3,10 & 3,0 \\
4 & \multicolumn{1}{|c}{ a) серы } & 0,11 & 0,09 & 0,08 & 0,075 \\
& б)сульфирующихся & 16,2 & 14,0 & 12,0 & 11,0 \\
5 & Коксуемость, \% масс. & 0,12 & 0,095 & 0,08 & 0,07 \\
\hline
\end{tabular}

На рис. 1 представлено изменение цетанового индекса и кислотного числа в зависимости от ступеней экстракции.

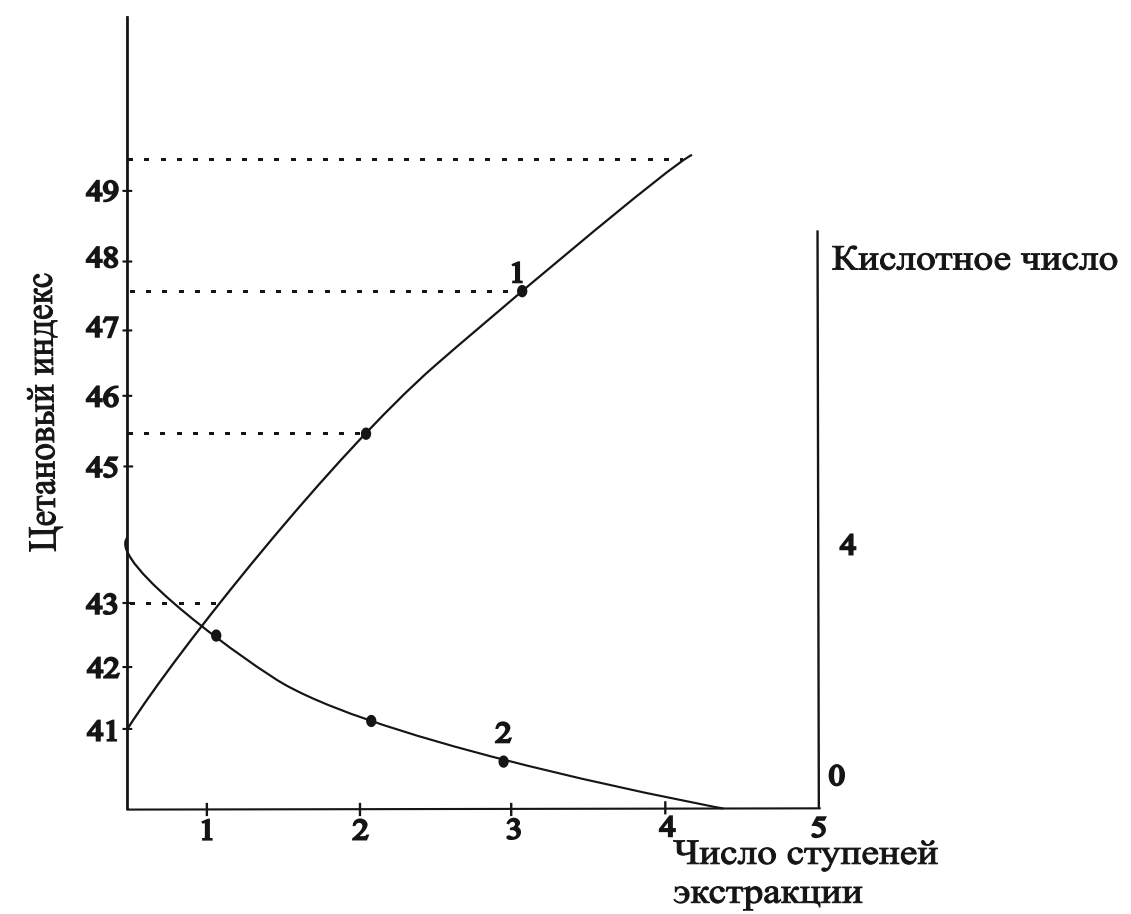

Рис. 1. изменение цетанового индекса и кислотного числа в зависимости от ступеней экстракции 1 - цетановый индекс
2 - кислотное число

Далее нами проводилась трёхступенчатая очистка с различным количеством растворителя.
Результаты исследований представлены в таблице 3.

Таблица 3. Результаты трёхступенчатой очистки

\begin{tabular}{|c|c|c|c|c|}
\hline \multirow[t]{2}{*}{ № } & \multirow[t]{2}{*}{ Показатели } & \multicolumn{3}{|c|}{ Количество растворителя к сырью } \\
\hline & & $1,5: 1$ & $0,9: 1$ & $0,5: 1$ \\
\hline 1 & Выход, \% масс & & & \\
\hline & а)рафинатной фазы & 57,9 & 51,2 & 47,9 \\
\hline & б)рафината & 78,5 & 77,8 & 77,1 \\
\hline 2 & Плотность рафината при $20^{\circ} \mathrm{C}$, кг $/ \mathrm{M}^{3}$ & & & \\
\hline & Вязкость при $20^{\circ} \mathrm{C}, \mathrm{Mм}^{2} / \mathrm{c}$ & 823 & 823 & 821 \\
\hline 3 & Содержание, \% масс.: & 3,20 & 3,15 & 3,09 \\
\hline 4 & a) серы & & & \\
\hline & б)сульфирующихся & 0,10 & 0,08 & 0,06 \\
\hline 5 & Коксуемость, \% масс. & 15,0 & 13,5 & 10,2 \\
\hline
\end{tabular}

Качество рафината и экстракта в обоих случаях очистки представлены в таблице 4. 


\begin{tabular}{lllllll} 
& ISRA (India) & $=\mathbf{3 . 1 1 7}$ & SIS (USA) & $=\mathbf{0 . 9 1 2}$ & ICV (Poland) & $\mathbf{= 6 . 6 3 0}$ \\
Impact Factor: & ISI (Dubai, UAE) $=\mathbf{0 . 8 2 9}$ & PUHL (Russia) $=\mathbf{0 . 1 5 6}$ & PIF (India) & $\mathbf{= 1 . 9 4 0}$ \\
& GIF (Australia) & $=\mathbf{0 . 5 6 4}$ & ESJI (KZ) & $=\mathbf{5 . 0 1 5}$ & IBI (India) & $\mathbf{4 . 2 6 0}$ \\
& JIF & $\mathbf{1 . 5 0 0}$ & SJIF (Morocco) & $=\mathbf{5 . 6 6 7}$ & & \\
\hline
\end{tabular}

Таблица 4. Качество рафината и экстракта

\begin{tabular}{|c|c|c|c|c|c|}
\hline \multirow[t]{2}{*}{ № } & \multirow[t]{2}{*}{ Показатели } & \multicolumn{2}{|c|}{$\begin{array}{c}\text { четырёх ступенчатая } \\
\text { экстракция }\end{array}$} & \multicolumn{2}{|c|}{$\begin{array}{c}\text { трёх ступенчатая } \\
\text { экстракция }\end{array}$} \\
\hline & & рафинат & экстракт & рафинат & экстракт \\
\hline 1 & Выход, \% масс & 76,5 & 23,5 & 77,1 & 22,9 \\
\hline 2 & Плотность при $20^{0} \mathrm{C}$, кг $/ \mathrm{M}^{3}$ & 820 & 992 & 821 & 1020 \\
\hline 3 & Вязкость при $20^{\circ} \mathrm{C}, \mathrm{Mм}^{2} / \mathrm{c}$ & 3,0 & - & 3,09 & - \\
\hline 4 & Содержание, \% масс.: & & & & \\
\hline & a) серы & 0,075 & 0,48 & 0,06 & 0,39 \\
\hline & б)сульфирующихся & 11,0 & - & 10,2 & - \\
\hline 5 & Коксуемость, \% масс. & 0,07 & - & 0,065 & - \\
\hline 6 & Кислотное число, мгКОН/Г & 0,1 & - & 0,09 & - \\
\hline 7 & Йодное число, гЈ $2 / 100$ г & 10,1 & 5,5 & 9,9 & 5,9 \\
\hline 8 & Цетановый индекс & 49 & - & 49,5 & - \\
\hline
\end{tabular}

Как видно из данных таблицы 4 качества рафината, полученного с различными ступенями очистки, но одним и тем же количеством растворителя очень схожи (8).

\section{Conclusion}

Таким образом из газойля коксования выделено сероорганические соединения, смолистые вещества, частично олефиновые углеводороды, повысился цетановый индекс.
Экстракционной очисткой ацетонитрил: пентаном $(1: 0,8)$ лёгкого газойля замедленного коксования можно получить компонент дизельного топлива, что экономически выгоднее, чем сжигать его как печное топливо, и увеличить объём вырабатываемого дизельного топлива. Экстракты можно использовать для производства технического углерода и компонента сырья окисленного битума.

\section{References:}

1. Mitusova, T. N., \& Loshnov, S. A. (2002). Uluchshenie smazyvajushhih svojstv dizel'nyh topliv. Neftepererabotka i neftehimija, Moskva, №1, 28-32.

2. Mitusova, T. N. (1999). Novye trebovanija k kachestvu dizel'nyh topliv. Himija i tehnologija topliv i masel, Moskva, №3, 7-10.

3. Nastrov, R. K. (1997). Jekologicheskaja strategija pererabotki nefti v Rossii. Himija $i$ tehnologija topliv i masel, Moskva, №3, 4-7.

4. Gajle, A. A., et al. (2011). Poluchenie komponenta dizel'nogo topliva mnogostadijnoj jekstrakcionnoj ochistkoj ljogkogo gazojlja zamedlennogo koksovanija. Himija $i$ tehnologija topliv i masel, Moskva, №5, 39-43.

5. Mugbil', H., Jusif-zade, A. A., \& Movsumzade, M. M. (2001). Ochistka dizel'nogo topliva metodom jekstrakcii aromaticheskih uglevodorodov. Neftepererabotka i neftehimija, Moskva, №8, 22-27.

6. Jusif-zade, A. A., et al. (2005). Poluchenie dizel'nyh topliv $s$ uluchshennymi jekspluatacionnymi svojstvami. (p.401-405). Uchjonye zapiski NII GTPN, gaza i himija. Baku.

7. Danilov, A. M. (2003). Vvedenie $v$ himmotologiju. (p.464). Moskva.

8. Gajle, A. A., et al. Poluchenie komponenta dizel'nogo topliva jekstrakcionnoj ochistkoj ljogkogo gazojlja zamedlennogo koksovanija. Himija i tehnologija topliv i masel, Moskva, №3, 7-10. 